\title{
La polivalencia periodística de los profesionales en las redes sociales ${ }^{1}$
}

\author{
Sonia GonZÁlez Molina \\ Universitat Jaume I (Castellón) \\ smolina@uji.es \\ Sara ORTELls BADENES \\ Universitat Jaume I (Castellón) \\ sortells@uji.es
}

Recibido: 30/07/2012

Aceptado: 26/10/2012

\section{Resumen}

La convergencia digital favorece los cambios en el perfil profesional de los periodistas, fomentando la polivalencia en la elaboración de los contenidos. Un nuevo panorama que se acentúa con la crisis, puesto que las empresas reducen plantillas y asignan nuevas tareas a sus redactores. Además, la proliferación del uso de las redes sociales en los medios también obliga a los periodistas a adquirir nuevas competencias para aprovechar eficazmente las nuevas plataformas. El objetivo de este artículo es conocer en profundidad las nuevas tareas que deben de desarrollar los periodistas, y como consecuencia, las competencias necesarias para llevarlas a cabo. La metodología utilizada incluye entrevistas en profundidad a diferentes perfiles profesionales del sector periodístico. Los resultados obtenidos reflejan que se están generando nuevas competencias relacionadas con tres grandes ámbitos: la gestión de la interacción con la audiencia, la distribución de contenidos, y la elaboración de los productos informativos.

Palabras clave: periodismo, innovación educativa, convergencia digital, redes sociales.

\section{The Journalistic Multiskilling of the Professionals in Social Networks}

\begin{abstract}
Digital convergence favours the changes that journalistic profile is experiencing. This scenario increases the journalistic multiskilling in the creation of news. The crisis emphasizes this panorama, as mass media tend to reduce their newsroom staff, assigning new tasks to journalists. Moreover, the spread of the use of social networks also contributes to the modification of the journalistic profile, as they have to acquire new skills in order to use these platforms in an effective way. The aim of this paper is to know in depth the new tasks assign to journalists, and as a consequence, the skills they have to develop. We have used a methodology based on interviews made to different journalistic profiles. Results show that new skills are emerging related to: how to administer the interaction with the audience, how to distribute contents, and how to elaborate news.
\end{abstract}

Key words: Journalism, educational innovation, digital convergence, social networks.

\section{Referencia normalizada}

GONZÁLEZ MOLINA, Sonia y ORTELLS BADENES, Sara (2012): "La polivalencia periodística de los profesionales en las redes sociales". Estudios sobre el mensaje periodístico. Vol. 18, núm. especial octubre, págs.: 455-463. Madrid, Servicio de Publicaciones de la Universidad Complutense.

Sumario: 1. Introducción. 2. Definición y tipología polivalente. 3. Las competencias del periodista polivalente. 4. Objetivos y metodología. 5. Los organismos y sus redes sociales. 6. Los contenidos y las estrategias. 7. Las (nuevas) competencias periodísticas. 8. Conclusiones. 9. Referencias bibliográficas.

\footnotetext{
${ }^{1}$ Esta comunicación se engloba dentro del proyecto de I+D con referencia P11B2010-53 financiado por la Fundación Caixa Castelló-Bancaixa y la Universidad Jaume I.
} 


\section{Introducción}

La expansión de la convergencia comunicativa permite explicar las principales transformaciones experimentadas por los medios de comunicación en sus vertientes tecnológica, empresarial, profesional y de contenidos (Díaz Noci, 2010). Entendida como un proceso aún en desarrollo, la convergencia tiene sus orígenes en los procesos de digitalización y concentración empresarial que alteraron el ecosistema mediático entre finales del siglo pasado y comienzos del presente. Se define como la confluencia o integración de herramientas, espacios, métodos de trabajo y lenguajes que anteriormente se presentaban separados, lo que permite a los periodistas elaborar contenidos para múltiples plataformas usando los códigos propios de cada una de ellas (García Avilés, Salaverría y Masip, 2008).

Actualmente, los informadores desempeñan todo tipo de funciones dentro de la redacción de sus medios, desde grabar y montar sus propias piezas informativas en las televisiones, hasta redactar para la versión impresa y digital de algunos periódicos. Es decir, se han vuelto polivalentes. Una situación que la actual crisis económica acentúa puesto que las empresas apuestan por la reducción de costes y la optimización de los recursos, desembocando en denominaciones como la de periodista orquesta para aludir a esta realidad.

La última innovación con capacidad para introducir modificaciones en el perfil profesional de los periodistas son las redes sociales. Su proliferación reporta indudables beneficios, como el acceso a un número más elevado de fuentes, la difusión de los contenidos informativos a escala global o la interacción con la audiencia. Este artículo se centra en detectar y analizar las nuevas aptitudes y habilidades que necesita el periodista que incorpora las redes sociales a su trabajo.

\section{Definición y tipología polivalente}

La polivalencia alude a la capacidad de ejercer diversas tareas simultáneamente y de manera habitual, ya sea para buscar, tratar o difundir informaciones sobre temas diversos, para diferentes soportes e interactuando con la audiencia (Deuze, 2004). Se desencadena a partir de las sucesivas innovaciones que ha experimentado la comunicación en los últimos años, que han alterado el perfil del periodista tradicional, mutándolo o provocando su desaparición en favor de otras figuras profesionales con competencias más acordes a las exigencias del nuevo entorno (Scolari et al., 2008). Rintala y Suolanen (2005) identifican las siguientes transformaciones:

- La transferencia de tareas: Las funciones que ejecuta un profesional las aborda otro.

- La fusión de roles tradicionales: Un mismo trabajador ejecuta las funciones de varios.

- El aumento de las funciones a asumir: El profesional asume las nuevas actividades que aparecen vinculadas a los nuevos medios.

- A partir de lo anterior, podemos establecer tres modelos de polivalencia:

- Polivalencia mediática: El periodista se ve obligado a elaborar informaciones para diferentes soportes.

- Polivalencia temática: El periodista se ve obligado a elaborar informaciones de diferentes ámbitos o secciones. 
- Polivalencia tecnológica: El periodista se ve obligado a hacerse cargo de todo o parte del proceso productivo de la información (Micó, 2006).

En el caso específico de los gabinetes de prensa y comunicación, González Molina (2011) añade la polivalencia funcional por la que los periodistas que trabajan en estas oficinas se ven obligados a asumir funciones de diversa naturaleza, algunas de ellas más cerca de la Publicidad y las Relaciones Públicas (relativas al merchandising, organización de congresos, etc.) que del Periodismo (redacción de notas de prensa, dosieres, etc.).

\section{Las competencias del periodista polivalente}

Las primeras aproximaciones para determinar las aptitudes de un periodista polivalente se centraban especialmente en el dominio del aspecto tecnológico para extraer el máximo rendimiento a las nuevas herramientas interactivas, hipertextuales y multimedia que la digitalización ponía en manos de los profesionales (Gil, 1999). Aunque la pericia técnica sea necesaria, la visión actual sostiene que lo importante para un periodista polivalente es que sepa tratar adecuadamente la información y responder de su fiabilidad (Martín Bernal, 2012: 83). En este sentido, Micó (2011) detalla las siguientes habilidades: detectar potencial informativo en hechos recientes, documentarse adecuadamente y obtener los datos necesarios para elaborar la información, presentarla de manera correcta eligiendo previamente los géneros, formatos o canales más adecuados para su difusión, y, por último, hacer el seguimiento oportuno de la pieza en cuestión, lo que incluye gestionar las sugerencias y comentarios del público. Aunque se refiere a los trabajadores audiovisuales, este perfil es extrapolable al resto de periodistas polivalentes.

De una manera más genérica, el mismo autor señala que el profesional polivalente debe de tener iniciativa, pensamiento analítico, dotes de planificación y organización, creatividad y ha de trabajar orientado a la consecución de objetivos. Además, de preocuparse por el orden y la calidad, debe ser capaz de trabajar en equipo y cooperar con sus compañeros y ser flexible (Micó, 2011: 201-202).

La irrupción de las redes sociales en el ámbito del Periodismo obliga a los informadores a incorporarlas en su trabajo. Su principal valor añadido es que permite al informador interactuar con su público. Es por ello que habilidades como saber participar en esta conversación, organizarla informativamente y movilizarla ganan protagonismo. Como también lo hace la capacidad de generar nuevas narrativas a partir de la integración de herramientas como Facebook, Twitter o Youtube en el discurso informativo (Martín Bernal, 2012).

\section{Objetivos y metodología}

El objetivo principal de este trabajo es conocer en profundidad las nuevas habilidades que deben de desarrollar los profesionales de la información a partir de la introducción de las redes sociales en su ámbito de trabajo. Por un lado, se identifican y definen las nuevas destrezas necesarias para llevar a cabo su trabajo satisfactoriamente. Por otro, se plantea la manera de introducir estas nuevas competencias en la forma- 
ción de los periodistas, haciendo especial hincapié en aquellas materias relacionadas con el ámbito del ciberperiodismo.

Se ha seguido una metodología cualitativa, basada en las entrevistas en profundidad a profesionales del sector periodístico de dos ámbitos diferenciados de la profesión. Por un lado, un medio de comunicación, Canal 9, la cadena de televisión pública valenciana, y por otro, el gabinete de prensa y comunicación del Servei Català de Trànsit (SCT) dependiente de la Generalitat de Catalunya. El perfil de los entrevistados se corresponde con el de periodistas y responsables para tener la visión estratégica y la del día a día, según sus propias necesidades.

\section{Los organismos y sus redes sociales}

Canal 9 es la cadena de televisión pública de la Comunidad Valenciana, integrada en el grupo Radiotelevisió Valenciana (RTVV). Emite desde 1989, y en 1995 puso en marcha su primera página web. Ante el auge que experimenta el consumo de contenidos a través de la red, en 2009 se crea el Departamento Multimedia que se encarga exclusivamente de la gestión y control de los contenidos difundidos online. Ese mismo año empiezan a utilizar las redes sociales de manera experimental. En 2011 el portal multimedia se renueva y ya integra completamente las redes sociales y los formatos multiplataforma adaptados para dispositivos móviles y tabletas.

El departamento está dividido en dos grupos diferenciados: el departamento web y teletexto, con un perfil más técnico; y la sección de contenidos y social media formada por 9 periodistas, 4 asesores lingüísticos y dos community manager.

El director del Departamento Multimedia explica que la apuesta por la integración de las redes sociales a la página web del ente responde a una necesidad de impulsar la difusión de los contenidos de producción propia y de potenciar la interacción con la audiencia. RTVV cuenta con un canal en Youtube y varios perfiles en Twitter, entre los que destacan@RTVV y @Nou24RTVV como canal de distribución de noticias. Asimismo, cuenta con más de una treintena de perfiles en Facebook.

Por su parte, el Servei Català de Trànsit (SCT) es un organismo autónomo que depende del Departamento de Interior de la Generalitat de Catalunya que funciona desde el 1 de diciembre de 2000. Se encarga de gestionar la movilidad en este territorio de manera que la circulación sea fluida y segura para conductores y peatones. Cuenta con un gabinete de prensa y comunicación que se encarga, entre otras funciones, de las relaciones informativas con los medios de comunicación y la planificación de campañas institucionales de prevención de accidentes de tráfico. El equipo lo integran una responsable y cinco periodistas, todas mujeres. Sus tareas son muy diversas, ya que incluyen la redacción de notas, convocatorias y dosieres de prensa y de artículos para la revista corporativa, la gestión de merchandising, la preparación de campañas de publicidad, la organización de congresos... No existe una especialización sino que todas hacen de todo, con lo que su filosofía de trabajo es claramente polivalente.

Desde finales de 2011, el SCT está presente en las redes sociales, primero en Twitter (diciembre de 2011) y luego en Youtube (marzo de 2012). En el primero, cuentan con 35 perfiles, uno por cada vía principal o red básica vial de Catalunya, que se actualizan automáticamente a partir de la información contenida en el Concentrador 
d'Informació de Trànsit (CIT), una base de datos que sirve para gestionar la informació sobre movilidad en Catalunya que también nutre la web del organismo (www.gencat.cat/transit). Existe otro perfil genérico (@transit)de cuya gestión y mantenimiento se encarga el gabinete de prensa, más concretamente, la periodista que en aquel momento esté trabajando.

\section{Los contenidos y las estrategias}

Los resultados obtenidos revelan que cada uno de los medios analizados utiliza las redes sociales con un objetivo y una estrategia determinada. En el caso de Canal 9 se usan: a) como una vía de diálogo directo con la audiencia, b) como plataforma de difusión de los contenidos de producción propia, c) como fuente informativa, y d) como parte de la estrategia comercial para captar nuevos inversores publicitarios. Por lo que respecta al Servei Català de Trànsit se aprecian ciertas diferencias respecto a Canal 9, en este caso se utilizan para: a) difundir información de servicio sobre tráfico, b) informar a los periodistas de las actividades del organismo, y c) como plataforma complementaria de difusión de contenidos informativos.

Si analizamos en profundidad el tipo de contenidos que se difunden a través de las diferentes redes sociales, encontramos diferencias significativas. En ambos casos, pero con ciertos matices, Twitter se utiliza como herramienta de difusión de información de servicio público. La televisión pública valenciana, cuenta con el perfil @Nou24RTVV que está diseñado específicamente para mantener informado a sus seguidores. Por un lado, se ofrecen titulares de informaciones de última hora de las que no se disponen imágenes, y por otro, noticias completamente acabadas elaboradas por el equipo de redacción del telenoticias. Las piezas informativas producidas para el noticiero se difunden simultáneamente en el medio televisivo, el portal multimedia y las redes sociales. El equipo de redacción del Departamento multimedia es el encargado de adaptar la noticia televisiva y subirla a la red.

Por otro lado, el perfil @RTVV se utiliza para que los redactores tengan acceso a diferentes fuentes de información, como por ejemplo, las notas de prensa del Tribunal Superior de Justicia De esta manera, para los profesionales de Canal 9, Twitter se ha convertido en una fuente de consulta fiable e instantánea que los mantiene actualizados con novedades informativas.

Por su parte, el Servei Català de Trànsit utiliza Twitter para ofrecer a los ciudadanos, incluyendo periodistas, información sobre incidencias viales (carreteras cortadas, retenciones...) y accidentes muy graves. En el perfil que se actualiza desde el gabinete de prensa y comunicación, se informa sólo sobre aquellos sucesos de importancia, no sobre retenciones habituales, que vienen recogidas en los 35 perfiles restantes que tiene el organismo. Además, se tuitean las notas y dosieres de prensa que elaboran y también algunas piezas informativas de la revista corporativa digital Infotrànsit, con lo que se fomenta la difusión de contenidos propios a través de varias plataformas coordinadas entre sí.

El organismo decidió incorporar las redes sociales un poco por inercia, al comprobar la aceptación de estas herramientas entre su público. Se buscó aprovechar su empuje, especialmente en el caso de Twitter, para distribuir información de tráfico 
pero también de otros temas, como por ejemplo las campañas preventivas o consejos de seguridad vial, de las que se pretende que haya una gran difusión viral, según palabras de la responsable de prensa y comunicación de la institución. Por política corporativa, no se contestan las preguntas, dudas o mensajes en general que formule el público desde las redes, por lo que la opción al diálogo con la audiencia o los periodistas es inexistente.

Las periodistas de la oficina han incorporado Twitter como una herramienta más de su trabajo. Cuando detectan una incidencia vial que consideran de importancia recurren a este servicio de microblogging para informar a la audiencia. Actualizan la información a medida que aparecen nuevos datos y concluyen el incidente cuando ya ha finalizado. En este caso, se trata de una información complementaria a la que aparece por defecto en la página web del organismo, donde también se puede seguir la evolución del suceso a través de una tabla alfanumérica, un mapa interactivo y las crónicas digitales colgadas en el sitio: permite ampliar detalles (porque se ofrecen nuevos datos), jerarquizar la información (porque no se tuitea todo sino lo más significativo) y hacer el suceso más comprensible (porque no se utiliza vocabulario técnico presente en la tabla y el mapa interactivo anteriormente citados).

Ocurre lo mismo con Youtube, donde se cuelgan los reportajes y entrevistas de esta última publicación, que elabora un equipo externo al gabinete, con los que tiene obligatoriamente que coordinarse. Las periodistas del gabinete también se ocupan de tuitear las notas de prensa, dosieres de prensa, los vídeos de las campañas de prevención de tráfico o los de la revista corporativa, también disponibles en Youtube, de los que elaboran los guiones y locutan. De esta manera, no sólo se distribuye la información por un canal más sino que se genera tráfico hacia el sitio web del SCT, siguiendo una estrategia de distribución multiplataforma de reutilización de los contenidos que genera el organismo.

En el caso de RTVV el canal de Youtube se utiliza únicamente como vía para alojar ganchos que redirijan a la audiencia al portal multimedia del ente. La principal característica que diferencia ambos medios es la apuesta por la interacción con los ciudadanos que hace Canal 9 a través de sus perfiles de Facebook. La información que se ofrece en Twitter está enlazada con la segunda plataforma citada, es decir, ambas comparten un gran volumen de contenidos. La diferencia reside en el hecho de que desde Facebook se fomenta además la interacción con la audiencia. En espacios como En connexió, programa de infoentretenimiento, esta red social se utiliza para encontrar nuevos temas y testimonios a partir de la propuesta de los espectadoresusuarios, que aproximadamente en el $20 \%$ de los casos acabarán convirtiéndose en noticia (Ortells, 2011).

El papel de los redactores del Departamento Multimedia es fundamental en la dinamización de la estrategia de difusión de los contenidos puramente informativos en formato multiplataforma. Por lo que respecta a los contenidos de programas y series de ficción, es el community manager el encargado de establecer los ganchos que se lanzaran desde los diferentes perfiles para captar a los espectadores. En definitiva, el equipo del Departamento Multimedia gestiona toda la información que se distribuye a través de las redes sociales y la página web, trabajando conjunta y coordinadamente con los diferentes equipos de cada uno de los programas. 


\section{Las (nuevas) competencias periodísticas}

De lo anteriormente expuesto, se deduce que las competencias periodísticas de carácter general que debe atesorar un profesional en las redes sociales son las siguientes:

- Saber titular: Para atraer el interés de la audiencia y redireccionarla hacia las páginas web corporativas o las producciones informativas propiamente dichas. Esta habilidad adquiere mayor relevancia si se tiene en cuenta el breve espacio existente para escribir en una plataforma como Twitter.

- Saber seleccionar contenidos: Ya que no todas las informaciones, materiales y recursos son susceptibles de ser difundidos a través de las redes sociales.

- Saber adaptar los contenidos para consumirlos a través de la red: Una mera transposición de las piezas informativas tradicionales al entorno de los social media limitaría el total aprovechamiento de las características inherentes a plataformas como Twitter o Facebook.

- Saber incitar la interacción con la audiencia: Para aprovechar la capacidad de las redes sociales para generar conversaciones con los usuarios, lo que redundaría en la obtención nuevos temas, puntos de vista, testimonios informativos, etc.

- Saber gestionar la relación con la audiencia: No sólo es necesario saber incitar al diálogo sino también saber cómo conducirlo para que la audiencia no sienta que no se la tiene en cuenta.

Aparte, como competencias generales, podemos destacar:

- Planificación y organización: Para saber generar el correcto trasvase de los contenidos hacia las redes sociales.

- Iniciativa: Para comunicar con agilidad y rapidez los contenidos a través de estas plataformas, en las que prima la inmediatez.

- Colaboración y cooperación: Con otros departamentos que producen contenidos.

- Compromiso por la calidad: Obligatorio si se quiere distribuir información con estos estándares en un entorno marcado por la rapidez o el contacto con el usuario.

Estas habilidades permitirían a) elaborar productos informativos óptimos para las plataformas sociales b) gestionar adecuadamente la distribución de estos contenidos y c) la relación con su audiencia. Por su transversalidad, las últimas competencias pueden encontrarse a lo largo de todo el itinerario académico del Grado de Periodismo. Por el contrario, las citadas en primer lugar, más específicas, son especialmente idóneas para aquellas asignaturas relacionadas con el ciberperiodismo, una materia que se centra en la elaboración de producciones informativas para el entorno digital y desde la que se puede abordar su diseño y adaptación para la difusión y consumo a través de las redes sociales. Con todo, sería deseable una coordinación docente con aquellas materias centradas en la redacción por un lado, para tratar los aspectos relacionados con la titulación, y con la confección de productos audiovisuales por el otro, por las adaptaciones que puedan necesitar las piezas de esta naturaleza para su consumo a través de estas plataformas móviles. 


\section{Conclusiones}

El trabajo de campo en Canal 9 y el SCT demuestra que la polivalencia no es un rasgo homogéneo, ya que depende de factores como el funcionamiento interno de los organismos o los objetivos comunicativos que se pretenden alcanzar. Los periodistas de ambas organizaciones adoptan su propio perfil polivalente, estimulando en cada caso unos rasgos en favor de otros. Así, en el Servei no se contempla el diálogo con los usuarios, por lo que no son pertinentes las habilidades relacionadas con el estímulo de la interacción con los ciudadanos ni con los periodistas: el uso de las redes sociales se limita a la inserción de titulares y notas de prensa y a reproducir contenidos ya difundidos por otras plataformas. Por el contrario, para Canal 9 se trata de un elemento significativo para desarrollar su trabajo informativo. No obstante, sus periodistas no desempeñan varias funciones, ya que cuentan con un departamento, el multimedia, dedicado exclusivamente a la producción de los contenidos que se ofrecerán a través de la red. Son los redactores de esta última área los que se encargan de adaptar esos mismos contenidos para colgarlos en la red.

Con todo, el manejo de las redes sociales amplía el perfil polivalente que se les presupone a los periodistas. Se constituye como uno de los valores futuros que deberá adquirir el profesional del periodismo. Es por ello pertinente dotar al alumnado del este Grado de las capacidades necesarias para afrontar una nueva realidad laboral polivalente. A través de seminarios y talleres específicos, el alumnado puede aprender a utilizar correctamente el lenguaje que precisan las redes sociales, así como a diseñar y adaptar productos informativos para difundirlos en estas plataformas. Y a desarrollar competencias como la capacidad de redactar titulares para las redes sociales, a seleccionar los contenidos más adecuados para ser difundidos en estas plataformas, a adaptar los contenidos a cualquier formato, a incitar la interacción con la audiencia y a gestionar esa relación con los usuarios. Asimismo, estos planes de formación se pueden utilizar también para que profesionales asentados reciclen sus conocimientos y se adapten a las nuevas exigencias del panorama mediático.

\section{Referencias bibliográficas}

DEUZE, Mark (2004): “What is multimedia journalism?”, en Journalism Studies, vol. 5, núm. 2, pp. 139-152.

DÍAZ-NOCI, Javier (2010): "Medios de comunicación en Internet: algunas tendencias", en El profesional de la información, noviembre-diciembre, vol. 19, núm. 6, pp. 561-567.

GARCÍA AVILÉS, José Alberto; SALAVERRÍA, Ramón, MASIP, Pere (2008): “Convergencia periodística en los medios de comunicación. Propuesta de definición conceptual y operativa", en I Congreso de la Asociación Española de Investigadores en Comunicación. Santiago de Compostela. Disponible en:www.aeic.org/santiago2008/contents/pdf/. comunicaciones/134.pdf. [Consultado el 20 de agosto de 2012]

GIL, Quim (1999): “Diseñando el periodista digital”, en Sala de prensa, vol. 2, núm. 13. Disponible en: www.saladeprensa.org/art89.htm. [Consultado el 20 de agosto de 2012] 
GONZÁLEZ MOLINA, Sonia (2011): La convergencia en els gabinets de premsa $i$ comunicación: el cas de les oficines especialitzades en seguretat viària. Barcelona, Universitat Ramon Llull. Tesis doctoral.

MARTÍN BERNAL, Obdulio (2012): "Los nuevos perfiles profesionales y laborales", en DIEZHANDINO, María Pilar: El periodista en la encrucijada. Barcelona, Ariel, Fundación Telefónica.

MICÓ, Josep Lluís (2006): Periodisme a la xarxa. Llenguatge nou d'un ofici vell. Vic, Eumo Editorial.

MICÓ, Josep Lluís (2011): "Periodistas audiovisuales inmóviles ante el periodismo multimedia móvil", en CASERO RIPOLLÉS, Andreu \& MARZAL FELICI, Javier (eds.): Periodismo en televisión. Nuevos horizontes, nuevas tendencias. Zamora, Comunicación social.

ORTELLS, Sara (2011): "Infoentretenimiento y redes sociales, nuevas herramientas para captar a la audiències", en IV Congreso sobre análisis filmico: Nuevas tendencias e hibridaciones de los discursos audiovisuales en la cultura digital contemporánea, Universitat Jaume I. Disponible en: http://hdl.handle.net /10234/30908. [Consultado el 10 de septiembre de 2012].

RINTALA, Niina\& SUOLANEN, Sanna (2005): "The Implications of Digitalization for Job Descriptions, Competencies and the Quality of Working Life", en Nordicom Review, vol. 26, núm. 2, pp. 52-67.

SCOLARI, Carlos et al. (2008): "El periodista polivalente. Transformaciones en el perfil del periodista a partir de la digitalización de los medios audiovisuales catalanes", en Zer, vol. 13, núm. 25, pp. 37-60

\section{Sonia GONZÁLEZ MOLINA}

smolina@uji.es

Profesora Ayudante (Universitat Jaume I)

Departament de Ciències de la Comunicació

Facultat de Ciències Humanes i Socials

Universitat Jaume I

Campus de Riu Sec, s/n

\section{Sara ORTELLS BADENES}

sortells@uji.es

Profesora Ayudante (Universitat Jaume I)

Departament de Ciències de la Comunicació

Facultat de Ciències Humanes i Socials

Universitat Jaume I

Campus de Riu Sec, s/n 